\title{
Development of intensity duration frequency curve, equation and nomograph for Udaipur
}

\section{Harshvardhan Baghel}

Author for Correspondence : Harshvardhan Baghel Office of Watershed Development and Soil Conservation, Panchayat Samiti, Pindwara, Sirohi (Rajasthan) India Email: harshvicky11@gmail. com
- ABSTRACT : For most water engineering projects, estimation of peak intensity of rainfall for different return periods using IDF curves are necessary. These curves are pre-requisite for planning, design, management of various hydraulic structures, urban storm water drainage and water conservation structures. IDF curves can be developed through the application of appropriate statistical distributions based on the historic records of rainfall data. In this paper a mathematical relationship has been developed between maximum intensity of rainfall and Return Period $(5,10$, $25,50,100,200,300,400,500$ and 1000 years) for various rainfall duration $(1,2,3,6,12$ and 24 hour $)$ using best fit distribution. 28 years (1986-2014) of rainfall mass curves have collected and analyzed to get rainfall intensities for various durations from raingauge station installed in Meteorological Observatory, College of Technology and Engineering campus, Udaipur. Around 03 different probability distributions model (Gamble's extreme value type I, Logpearson type III, Normal distribution) were used to evaluate maximum rainfall intensity for various durations. KolmogorovSmirnov and Chi-squared tests were used for the goodness of fit of the probability distributions. Results showed that Gumbel distribution found to be have least critical values for both the tests for all durations hence consider as the best fit distribution for given sample population. The derived precipitation intensities were utilized for generation of intensity duration frequency curve and equation. A nomograph has also developed with 03 parallel parameter scale using method suggested by Luzzadar (1964) to represent this relationship in a graphical form.

- KEY WORDS : Chi-square, Kolmogorov-smirnov, Nomograph, IDF equation

-HOW TO CITE THIS PAPER : Baghel, Harshvardhan (2020). Development of intensity duration frequency curve, equation and nomograph for Udaipur. Internat. J. Agric. Engg., 13(1) : 42-47, DOI: 10.15740/HAS/IJAE/13.1/42-47. Copyright@ 2020: Hind Agri-Horticultural Society. 